\title{
MEMÓRIA E TRADIÇÃO: jornais centenários em busca de sobrevivência em tempos de convergência midiática
}

\author{
Hérica Lene Brito ${ }^{1}$
}

\begin{abstract}
Resumo: Este artigo busca discutir o contexto de crise do meio de comunicação jornal impresso - considerandoo como "lugar de memória" (NORA, 1993) - a partir das estratégias de sobrevivência de seis periódicos com mais de 100 anos de circulação no país, fundados no final do séc. XIX. Esta abordagem faz parte da pesquisa Jornais centenários do Brasil: como e por que sobrevivem em tempos de convergência midiática?. A metodologia foi levantamento bibliográfico, pesquisa nos sites dos jornais e entrevistas com seus dirigentes (diretores, editores ou chefes de redação). A abordagem teórica envolve os conceitos de memória, história, tradição, jornalismo e convergência cultural e midiática.
\end{abstract}

Palavras-chave: Comunicação, memória, história, tradição, jornais centenários.

\begin{abstract}
This paper discuss the context of the crisis of the newspaper print media - considering it as "place of memory" (NORA, 1993) - from the survival strategies of six periodicals with more than 100 years of circulation in the country, founded at the end of the century. XIX. This approach is part of the research The centenarian newspapers of Brazil: how and why they survive in times of media convergence?. The methodology was a bibliographical survey, a search on the newspaper sites and interviews with its directors (directors, editors or editors). The theoretical approach involves the concepts of memory, history, tradition, journalism, and cultural and media convergence.
\end{abstract}

Keywords: Communication, memory, history, centennial newspapers, multimedia convergence.

\section{Introdução}

"A indústria jornalística está morta, mas o jornalismo segue vivo em muitos lugares." Esta é a tese do relatório Jornalismo pós-industrial: adaptação aos novos tempos (ANDERSON, BELL \& SHIRKY, 2012), preparado no âmbito do Tow Center for Digital Journalism da Escola de Jornalismo da Universidade Columbia, que mostra que as instituições atuais estão perdendo receita e participação de mercado e, se quiserem manter ou mesmo aumentar sua relevância, têm de explorar novos métodos de trabalho e processos viabilizados pelas mídias digitais.

Nesse contexto de jornalismo pós-industrial ${ }^{2}$, quais estratégias jornalísticas e mercadológicas os periódicos mais antigos do país estão empreendendo para se manter

\footnotetext{
${ }^{1}$ Jornalista (UFES, 1997), doutora em Comunicação e Cultura (UFRJ, 2009), mestre em Comunicação (UFF, 2004), especialista em Estratégias em Comunicação Organizacional (Faculdade Cândido Mendes de Vitória-ES, 2001) e professora do curso de graduação em Comunicação (Jornalismo e Publicidade) e do Mestrado em Comunicação da Universidade Federal do Recôncavo da Bahia (UFRB) desde 2011.

${ }^{2}$ Termo empregado em 2001 pelo jornalista Doc Searls para sugerir um "jornalismo que já não é organizado segundo as regras da proximidade do maquinário de produção" (ANDERSON, BELL \& SHIRKY, 2013).
} 
circulando? Esta questão é a tônica da pesquisa Jornais centenários do Brasil: como e por que sobrevivem em tempos de convergência midiática $?^{3}$, que visa contribuir para os estudos de História dos Meios de Comunicação ou das Mídias, entendendo ambos como parte de um campo mais amplo: História da Comunicação. De acordo com levantamento da Associação Nacional dos Jornais (ANJ), existem 28 impressos com mais de 100 anos em circulação no país.

A metodologia envolveu levantamento bibliográfico sobre História da Imprensa e sobre os jornais pesquisados e realização de entrevistas com dirigentes (diretores, editores ou chefes-redação) a partir de um questionário semiaberto.

Ao buscar os depoimentos, levamos em conta que as lembranças, apesar de pertencerem aos indivíduos, se originam na sociedade. Os sujeitos só lembram a partir do ponto de vista de um grupo social específico, ao qual de alguma forma se vinculam (HALBWACHS, 1990). Memória é experiência vivida, configurada pela dialética lembrança e esquecimento, lugares de disputas, conflitos (NORA, 1993). É um processo de ordenamento, de produção de sentido, que pressupõe enquadramentos, esquecimentos e silêncios (POLLAK, 1989).

Em busca dos relatos sobre os longevos, obtivemos retorno dos dirigentes de 15 dos 28 jornais, até março de 2018. Neste artigo, especificamente, o recorte são os seis periódicos fundados no final do século XIX: O Fluminense (1878); Tribuna do Norte (1882); Gazeta de Minas (1887); O Taquayrense (1887); Gazeta de Ouro Fino (1892); e A União (1893).

Esta abordagem encontra-se dividida em três partes: na primeira se discute o atual contexto do jornal impresso; a segunda trata do valor da tradição para os jornais centenários e, na última, aborda-se estratégias de aproximação com seus públicos.

\section{A crise e o jornal impresso}

O jornal impresso vai mesmo acabar? Longe de existir um consenso que dê conta de responder a esta pergunta, não faltam previsões - sobretudo desde o final do século XX -

\footnotetext{
${ }^{3}$ Pesquisa apoiada pelo CNPq (edital Universal 2014) e que continua sendo desenvolvida em nível de pósdoutorado. Tem como aportes teóricos as abordagens sobre memória de autores como Henri Bergson (1990), Maurice Halbwachs (1990), Jacques Le Goff (1990), Michel Pollak (1989; 1992), Pierre Nora (1993) e Paul Ricouer (1997; 2001); sobre as intersecções entre memória, história e jornalismo de Marialva Barbosa (2000; 2004; 2004a; 2005; 2005a; 2006; 2007; 2007a; 2007b; 2009; 2011; 2013) e Ana Paula Goulart Ribeiro (2000; 2003; 2007; 2008; 2009); e sobre convergência cultural e midiática de Henry Jenkins (2009) e Rámon Salaverría e Samuel Negredo (2008).
} 
sobre o fim do jornal em função da consolidação do paradigma digital e do crescimento da internet como suporte para o jornalismo veiculado na web.

Precursor de todas as modalidades jornalísticas, o jornal desempenhou um importante papel na constituição de um modelo de sociabilidade que compartilhamos atualmente, quando vivenciamos um regime dramaticamente dependente dos conteúdos de mídia.

Nos últimos anos, o Brasil presenciou o fechamento de vários periódicos, como o tradicional Jornal do Commercio, do Rio de Janeiro, fundado em 1827, e que circulou por 189 anos (sua última edição foi dia 29 de abril de 2016); e o Jornal da Tarde, o Marca Brasil e o Mais Esportes, que também foram extintos.

Durante a pesquisa sobre os jornais centenários, outro importante periódico, o Jornal do Brasil, deixou de circular em em 31 de agosto de 2010 e passou a ser apenas digital. No entanto, em fevereiro de 2018, voltou a circular no estado do Rio de Janeiro, após um novo controlador ter assumido a empresa, em 2017, com um plano de retomada da versão impressa (RANGEL, 2017; SÁ, 2018).

Outro centenário que teve parou de circular foi o Diário de S.Paulo, de 1884, fundado em $1884^{4}$ como Diário Popular. Em janeiro de 2018, a justiça decretou sua falência, suspendendo suas versões impressa e on-line, em decorrência da confusão societária envolvendo o jornal e as marcas Editora Fontana, Editora Minuano e Cereja Serviços de Mídia. Ele era o $7^{\circ}$ mais antigo em circulação no Brasil e o $3^{\circ}$ do Estado de São Paulo.

Dois outros centenários pararam de circular impressos e migraram definitivamente para a internet: $O$ Mossoroense (fundado em Mossoró/RN em 1872, passou a ser apenas online a partir de 31/12/2015) e o Jornal Correio Riograndense (fundado em Caixas do Sul/RS em 1909 e apenas on-line a partir de fevereiro de 2017). O Diário do Povo (fundado em Campinas/SP em 1912), cuja empresa anunciou que circularia somente on-line, a partir de 2012, no entanto, foi extinto.

Em 2013, foi divulgada uma pesquisa, realizado pela Future Exploration Network, que aponta o ano de 2027 como a época na qual não haverá mais impressos no Brasil. Os periódicos, então, acabariam em tão pouco tempo? É um prazo um tanto curto para anunciar a morte do jornal, que já sobreviveu a outros presságios mórbidos com o advento do rádio e da televisão na primeira metade do século XX.

\footnotetext{
${ }^{4}$ Foi fundado inicialmente como vespertino por José Maria Lisboa e Américo de Campos.
} 
A abordagem sobre essa questão é a tônica da obra de referência feita por Philip Meyer - Os jornais podem desaparecer? Como salvar o jornalismo na era da informação (2004) -, que traça um panorama dos modelos de jornais sustentados pela publicidade; mostra como os anunciantes estão reagindo às novas tecnologias e como a crescente influência dos investidores nas empresas jornalísticas afeta o produto que o leitor recebe.

Busca-se assim compreender esse fenômeno social complexo, em que a cadeia tradicional do jornalismo enfrenta a concorrência das redes sociais na distribuição de informações, demite/ profissionais da redação, reduz tiragens e vê ameaçado seu papel na constituição das sociedades democráticas (MEYER, 2007).

De qualquer forma, independente das previsões em torno da permanência ou não do jornalismo no suporte papel, os jornais são importantes fontes históricas e de informação para e sobre a sociedade. São importantes "lugares de memória" (NORA, 1993) ${ }^{5}$. No campo da comunicação, diversos autores que correlacionam em seus estudos mídia e história citam os meios de comunicação como um dos "lugares de memória" da contemporaneidade. ${ }^{6}$

Os jornais, criando diariamente grandes acontecimentos, ao selecionar, ao destacar ou ao relegar fatos ao esquecimento, operam uma seleção, no qual se valoriza aspectos e temas, em detrimento de outros. Na contemporaneidade, os meios de comunicação ajudam a eleger quais fatos devem ser considerados como importantes para a agenda da sociedade e que são por eles registrados, ou seja, os mais memoráveis portanto (BARBOSA, 2000, p.144). Dessa forma, acabam interferindo também na história a ser escrita e, por consequência, como um elemento da cultura da sociedade (RIBEIRO, 2003).

Ao se presumir que a mídia de maneira geral ou os meios impressos se constituem como lugares de memória, se está percebendo-os como espaços de articulação da memória coletiva de determinados grupos. Além disso, parte-se da constatação de que a história passou a ser dilatada a partir da ação midiática, passando a memória a ser articulada a partir das disputadas operadas no espaço midiático, forjando enquadramentos de memória. Nesse sentido, os meios de comunicação produziriam uma espécie de história do tempo presente, realizando para isso uma "operação midiográfica" (SILVA, 2011). Seriam, portanto, eles que

\footnotetext{
${ }^{5}$ Essa noção teve apropriações diversas a partir do texto-chave "Entre memória e história: a problemática dos lugares", que abre o volume inicial da obra Les Lieus de mémoire?. Pierre Nora os apresentou como lugares simultaneamente materiais, simbólicos e funcionais, se referindo principalmente aos monumentos e ao patrimônio cultural, nos quais a separação entre história e memória não seria rígida (GONÇALVES, 2012).

${ }^{6}$ Entre esses estudos citamos e Santos (2002), Ribeiro (2003), Ribeiro e Ferreira (2007), Barbosa (2007, 2008 e 2012), Gomes (2007), Silva (2009 e 2011), Novaes (2014) e Rêgo (2015).
} 
dariam espessura à história, sendo nesse sentido também lugares de memória (BARBOSA, 2016, p.11).

No Brasil, os jornais foram a principal fonte de informação durante mais de um século e meio. A imprensa se expandiu no século XIX. No século XX, sua supremacia não foi ameaçada pela chegada do rádio, na década de 1920. A época de ouro do impresso no país ocorreu nos anos 1950 e 1960, quando era o principal veículo de informação e de publicidade para as massas, cuja educação e capacidade de consumo estavam aumentando.

Os periódicos se beneficiaram do surgimento de uma classe média para quem a leitura era uma necessidade e um símbolo de status. Nas décadas seguintes, a TV tirou grande parte da publicidade deles e tornou-se a principal fonte de notícias para a maioria da população, mas os impressos continuaram sendo os meios de informação mais influentes (MOLINA, 2015 , p.28 e 29).

A chegada da internet, no entanto, afetou a imprensa diária de várias formas. Os jornais passaram a disponibilizar gratuitamente na rede o mesmo conteúdo pelo qual seus assinantes tinham que pagar. Um dos golpes mais profundos foi a perda de anúncios classificados, uma excelente fonte de receita, que levou à morte do tradicional Jornal do Commercio, por exemplo, e a migração de outros veículos longevos para versões on-line. A internet também propiciou o surgimento de serviços eletrônicos de informação sem nenhum vínculo com a mídia tradicional e que passaram a competir com ela.

Com as redes sociais, o público também pôde se transformar em canal de mensagens. Os jornais tentam adaptar-se e sobreviver. Perderam circulação e publicidade, e agora tentam, tardiamente, compensar essas perdas passando a cobrar pelo conteúdo. Para isso, precisam vencer a inércia e o hábito de ler sem pagar. É um novo modelo de negócio, no qual as empresas procuram depender mais da receita proveniente da versão digital e menos das edições impressas; mais da venda do conteúdo e menos da publicidade. O ponto de equilibro ainda não foi encontrado.

Apesar da crise, os jornais continuam sendo poderosas usinas de informação. Uma das vantagens que conservam é serem um meio mais propício à análise e à reflexão que os veículos eletrônicos. Suas informações são também mais confiáveis.

A função tradicional do jornal é editar todo esse caos de dezenas de milhares de notícias que são disponibilizadas na internet e hierarquizar a informação, dando mais destaque 
ao que considera mais importante e mostrando o contexto (MOLINA, 2015), o que pode contribuir para a sua sobrevivência em um contexto de convergência multimídia. ${ }^{7}$

Agora, há menos leitores do jornalismo impresso, cujas tiragens despencam. E menos anunciantes, que costumavam responder pela maior fatia das receitas. As diferentes mídias se concentram na internet, onde se colhe mais audiência e se busca, com dificuldades, o faturamento publicitário do passado.

\section{O valor da tradição para os jornais centenários}

Quais são as estratégias que jornais centenários estão lançando mão na tentativa de sobreviver à crise do jornalismo? Nossa abrangência neste artigo começa na região Sudeste, com $O$ Fluminense, - fundado em 8 de maio de 1878 e em circulação em Niterói (RJ) ${ }^{8}$, atualmente o mais antigo em circulação no estado do Rio de Janeiro e o $4^{\circ}$ do país, segundo a ANJ.

A diretora de Jornalismo Multimídia, Liliane Souzella (2017), afirmou que longevidade do $O$ Fluminense é entendida pela empresa como um capital simbólico importante para a manutenção do periódico: "a tradição e o conteúdo local são fundamentais para manter tanto os leitores quanto os anunciantes e parceiros".

No Estado de São Paulo, abordamos um jornal longevo aqui: o Tribuna do Norte (1882). Foi fundado pelo jurista, político e poeta João Marcondes de Moura Romeiro e está entre os mais antigos do Brasil ( $5^{\mathrm{a}}$ posição). Em sua unidade da federação, só perde para $O$ Estado de S.Paulo ${ }^{9}$. No que diz respeito à imprensa do interior, é líder absoluto em longevidade.

Para a atual presidente da Fundação Dr. João Romeiro e do Tribuna do Norte, Jucélia Batista, a tradição ajuda o periódico a sobreviver: "O jornal é muito conhecido e tem credibilidade em toda a região, formada por 39 cidades".

\footnotetext{
${ }^{7}$ Convergência é uma palavra que consegue definir transformações tecnológicas, mercadológicas, culturais e sociais, dependendo de quem está falando e do que imaginam estar falando. É o fluxo de conteúdos através de múltiplas plataformas midiáticas, à cooperação entre múltiplos mercados midiáticos e ao comportamento migratório dos públicos dos meios de comunicação, que vão até quase qualquer parte em busca das experiências de entretenimento que desejam (JENKINS, 2009, p.29).

${ }^{8}$ Seus fundadores foram o leiloeiro Prudêncio Luís Ferreira Travassos e o tipógrafo Francisco Rodrigues Miranda.

${ }^{9} O$ Estadão foi criado em 1875 e é o mais antigo em seu estado e o $3^{\circ}$ do Brasil.
} 
Seguindo para o sul do país, encontramos outro que está ancorado em sua tradição: $O$ Taquayrense, que, em tempos de convergência midiática, é um semanário ainda feito em tipografia em pleno século XXI, na cidade de Taquari, interior do Rio Grande do Sul. Fundado em 15 de julho de 1887 por Albertino Saraiva, teve sua $1^{\text {a }}$ edição no domingo 31 de julho desse mesmo ano. "Mantém-se desde sua fundação fiel ao velho sistema de Gutenberg, sendo possivelmente o único da América Latina a funcionar dessa maneira na atualidade", afirmou o redator-chefe Pedro Harry Dias Flores.

Manter o jornal em circulação é tido como uma "missão": "É preservar a essência de O Taquaryense, o modo singular como é produzido, letrinha por letrinha, num trabalho minucioso que requer muita paciência. É isso que o diferencia e encanta seus assinantes e anunciantes, de quem depende basicamente para sobreviver" (FLORES, 2017).

Um dos principais segredos dessa longevidade é a identidade que tem conservado ao longo dos tempos: "permanecendo leais às diretrizes traçadas pelo fundador Albertino Saraiva"(ibid.).

Fazendo o movimento de volta à região Sudeste, temos duas gazetas mineiras centenárias mineiras: de Minas e de Ouro Fino. No caso da Gazeta de Minas, fundada em 4 de setembro de 1887, na cidade de Oliveira, pelo português Antônio Fernal, com periodicidade semanal até hoje mantida, a tradição também é considerada um fator de sobrevivência. O jornalista-editor João Bosco Ribeiro, 31 anos de profissão, definiu a importância da seguinte forma:

\footnotetext{
O jornal está para a cidade de Oliveira como tradutor de sua rica história. Ou seja: o veículo é histórico não apenas sob o ponto de vista cronológico, mas sobretudo no que diz respeito à apresentação da realidade histórica local. Gazeta de Minas faz parte da rotina semanal da sociedade, que aguarda a circulação de suas edições para compreender, de fato, os fenômenos que perfazem sua vida hodierna. No jornalismo científico, a tradição só vale quando é portadora do novo, num sistema de comunicação sempre circular (interativo) e não apenas horizontal (feedback) (Ribeiro, 2018).
}

A Gazeta de Ouro Fino, fundada em 31 de janeiro de 1892 por Júlio Bueno Brandão (1858-1931), na cidade de Ouro Fino, depende totalmente da tradição, na avaliação de sua diretora-executiva, Ciça Ferraz (2018): "É o que mantém a Gazeta em pé. O simples fato de ela ser considerada patrimônio histórico de Ouro Fino".

Por muitos anos a Gazeta registrou fatos importantes não só de Ouro Fino como da região e do Brasil como um todo, que passou por grandes transformações: "Por esta questão 
tem em seu currículo muitas histórias marcantes de registros e fatos que fizeram a história" (FERRAZ, 2018).

Na região Nordeste, A União é um dos mais antigos em circulação. Fundado em João Pessoa, na Paraíba, em 2 de fevereiro de 1893, por Álvaro Lopes Machado (1857-1912), circula há 125 anos. O editor-geral Felipe Gesteira disse que há outros fatores, além da tradição adquirida com a longevidade, que ajudam a manter o jornal:

\begin{abstract}
Mesmo com uma equipe reduzida, A União desponta à frente de outros com sua farta publicação de artigos, além de ter o único suplemento exclusivamente literário, o Correio das Artes. E ainda, apesar de ser superavitário, o que já justifica a continuidade da circulação, o jornal deve permanecer no mercado por centenas de anos, pois a Lei Estadual 1.491/2017, sancionada pelo governador Ricardo Coutinho, reconhece o diário impresso A União como patrimônio da Paraíba (GESTEIRA, 2018).
\end{abstract}

Tradição, em sua definição mais simples, é um produto do passado que continua a ser aceito e atuante no presente. Para Max Weber, os comportamentos tradicionais são formas puras de ação social, ou seja, são atitudes que os indivíduos tomam em sociedade e são orientadas pelo hábito, pela noção de que sempre foi assim (SILVA \& SILVA, 2015, p.405408).

O conceito de tradição possui muitos significados: pode estar atrelada ao conservadorismo e ao resgate de períodos passados considerados gloriosos (visão clássica nas ciências sociais); pode ser inventada para legitimar novas práticas apresentadas como antigas (HOBSBAWM \& RANGER, 1997). Pode ser pensada como imóvel, mas hoje cada vez mais estudiosos percebem suas ligações com as mudanças.

A marca temporal atingida - ter passado dos 100 anos - é tido como um capital simbólico importante para a manutenção desses periódicos por parte das empresas localizadas em diferentes regiões do Brasil. Assim, aparece nas falas dos dirigentes a questão da tradição como patrimônio e fortalecimento das marcas e como um elemento que contribui, em algum nível, para a manutenção dos jornais longevos. 


\section{"Proximidade" como valor-notícia fundamental}

Os jornais longevos têm buscado valorizar a proximidade na abordagem das notícias em busca de atrair os leitores como um valor-notícia ou critério de noticiabilidade ${ }^{10}$ fundamental, além do investimento na plataforma da internet e da busca de canais de interação com os públicos.

Esta estratégia foi enfatizada pela diretora de Jornalismo Multimídia de $O$ Fluminense, Liliane Souzella, que colocou como estratégia mercadológica e jornalística em tempos de convergência multimídia o enfoque na produção de notícias locais, sobretudo sobre Niterói, São Gonçalo e todo o Leste Fluminense do Estado:

Este é um diferencial importante que nos destaca tanto para quem busca a informação quanto para quem precisa anunciar. Desde 2012, estamos trabalhando com conteúdo unificado no site, impresso, TV O FLU e Rádio Fluminense, respeitando as características próprias de cada mídia. Sabemos da importância que o impresso tem no mercado local, mas estamos acompanhando com extremo cuidado também a produção multimídia e a interação em redes sociais (SOUZELLA, 2017).

Sobre o relacionamento do jornal com seus públicos, $O$ Fluminense tem uma seção específica no site para receber as demandas dos leitores; também disponibiliza e-mails e WhatsApp para o recebimento de denúncias e sugestões de pautas.

No impresso, a página de Opinião reserva espaço para os textos e fotos enviados por leitores. A diretora destacou o projeto chamado "Você Faz a Notícia", em que os leitores pautam as equipes de reportagem. A rádio é uma das poucas que coloca os ouvintes no ar, ao vivo, durante a programação.

Segundo ela, a redação funciona de forma integrada ${ }^{11}$ (impresso e on-line no mesmo espaço), mas há jornalistas específicos para cada mídia, a fim de garantir o tratamento final à notícia de forma a atender as particularidades de site, da TV e do rádio. "Mas as apurações

\footnotetext{
${ }^{10}$ Noticiabilidade é o conjunto de elementos através dos quais o órgão informativo controla e gere a quantidade e o tipo de acontecimentos, de entre os quais há que selecionar as notícias, da qual fazem parte os valores-notícia (news values) - (WOLF, 1999, p.195).

${ }^{11}$ A integração é a confluência de dois ou mais unidades ou correntes em uma única. No âmbito jornalístico, refere-se à fusão de duas ou mais equipes redacionais em apenas uma, de modo que a redação resultante trabalha reunida em um mesmo ambiente físico, sob um mesmo gerenciamento editorial e com uma infraestrutura tecnológica comum. Do ponto de vista teórico, portanto, uma redação integrada é aquela com capacidade de alimentar de conteúdos dois ou mais meios a partir de uma única unidade de produção (SALAVERRÍA \& NEGREDO, 2008, p.51).
} 
são unificadas e, cada vez mais, nossos repórteres atuam de forma multimídia, com envio de flashes para o on-line, gravação de vídeos e áudios e entradas ao vivo”, explicou.

A proximidade com os leitores também tem sido a estratégia do Tribuna do Norte. A presidente do Tribuna do Norte, Jucélia Batista, disse que o periódico tem buscado mudar a linha editorial, criando novas editorias e cadernos como "Qual o Seu Talento?" que mostra pessoas e suas artes/vocação:

Isso atrai leitores e seguidores. Também temos buscado matérias com mais profundidade jornalísticas, séries e indicações de leituras (pelo leitor), o que traz uma interação maior. As pessoas adquirem o jornal para se ver e mostrar aos outros. Enfim, nosso lema é buscar identificação, proximidade (BATISTA, 2017).

O jornal tem buscado se relacionar com seus públicos, segundo ela, por meio das redes sociais (temos Facebook); do email oficial, por telefone e pessoalmente. E também divulgando a cidade, noticiando fatos sociais, culturais, educacionais, esportivos, classistas, religiosos, policiais etc.), além das notícias relacionadas aos departamentos ligados à prefeitura e Câmara Municipal.

Atualmente o Tribuna do Norte mantém uma seção destinada a publicar a opinião do leitor sobre filmes e livros e outra que visa estimular a criança (alunos de escolas do Nível Fundamental I) à leitura do periódico. A opinião dos estudantes sobre a matéria que julgou mais interessante é remetida ao jornal (carta) e publicada.

Sobre a linha editorial, afirmou: "É um jornal que recebe verba pública (repasse), por isso, dá prioridade as notícias do Executivo; mas também tem uma página do Legislativo (semanalmente) e matérias gerais da região: Cultura, Esportes, Economia, Educação. Só não trata de política diretamente".

Com relação ao tratamento da notícia do jornal impresso para o on-line, ela informou que não há diferença de conteúdo, produzido por uma única equipe que trabalha no fechamento das edições que serão impressas e, posteriormente, colocadas no site.

No Rio Grande do Sul, O Taquaryense mantém contato com seus públicos por e-mail, telefone e carta. Ele chegou a ter um site, criado há poucos anos por estudantes de jornalismo que realizaram uma pesquisa sobre o periódico, mas a página não está mais disponível. Flores disse que, em breve, querem criar outro site e, também, ingressar no Facebook, para disponibilizar os conteúdos publicados na versão impressa. 
Flores ressaltou que é difícil manter um jornal no interior: "As dificuldades se fazem sentir de maneira mais acentuada para a imprensa, sobretudo em se tratando de um jornal como $O$ Taquaryense, cujas limitações decorrentes de seu sistema de produção, há algum tempo 'fora de moda', não são poucas".

No caso da Gazeta de Minas, o editor João Bosco Ribeiro disse que, sob o ponto de vista mercadológico, estão utilizando ferramentas técnicas como a capacidade de difusão informativa do veículo e os níveis de conhecimento público da marca. Sob o ponto de vista jornalístico, apresentam, semanalmente, "material fotográfico e informativo exclusivo, análises exclusivas dos fatos de interesse do público-alvo e publicação de artigos e resenhas também exclusivos".

\footnotetext{
A credibilidade foi colocada como um fator importante para a sobrevivência do jornal: cuidamos ainda da isenção e da credibilidade do jornal, por meio de renúncia a negócios publicitários com os poderes públicos do município, mesmo que isso signifique quebra acentuada no faturamento. Quanto mais equidistante dos poderes políticos, mais credibilidade é acrescida ao jornal. Quanto mais desfrute de credibilidade, mais aceito o veículo é por seu público (RIBEIRO, 2018).
}

Outra estratégia enfatizada no discurso do editor foi a valorização da informação com tratamento técnico, rigor na apuração e apresentada em bom estilo literário e vernacular pelo jornal impresso, que o diferenciaria "da balbúrdia das redes sociais" e o ajudariam a ser viável, em plena era da convergência multimídia.

A Gazeta de Minas tem se relacionado com seus públicos por meio de suas próprias páginas, pelo portal na internet, redes sociais, canais multimídias, "intensa participação social", e, principalmente, contato direto com o leitor.

$\mathrm{Na}$ avaliação de Ribeiro, o fato de ser um jornal do interior é um fator de dificuldade para a operacionalização do veículo: "Quanto mais interiorano, mais difíceis são as condições de sobrevivência de um veículo de comunicação impresso, exatamente pela concorrência dos sistemas eletrônicos e pela alienação sociológica do Homem moderno".

Atualmente, ele destacou, os veículos impressos do interior padecem de uma crescente escassez de inserções publicitárias comerciais e uma severa diminuição do número de assinantes. "O futuro é extremamente incerto e dependerá do surgimento de novas alternativas", destacou.

A tiragem atual da Gazeta de Minas (inicio de 2018) é de um mil exemplares por semana, para um público-alvo de 4 mil leitores. A média de acessos ao site fica em torno de 3 
mil visualizações por edição. O município de Oliveira conta hoje com cerca de 42 mil habitantes.

Sobre as abordagens noticiosas no jornal impresso e no site, Ribeiro disse que não existem diferenças substanciais. No site, colocam textos menores e fazem chamadas para a edição impressa. A produção de conteúdo é feita pela mesma equipe e nas mesmas instalações.

O projeto é atualizar o site no início de 2019 para acrescentar uma série de novas possibilidades, com ênfase para a cobertura do município com reportagens, fotos, vídeos em tempo real e sistema mais moderno de cadastramento e pagamento de assinaturas. E manter a visualização das páginas do jornal com o mesmo conteúdo e leiaute impresso.

No caso do outro jornal mineiro abordado aqui, o Gazeta de Ouro Fino, ao longo de sua história, passou por reformas gráficas para se adaptar aos jornais da época e ficou com menos textos e mais fotos, ilustrações, charges. Atualmente, circula com uma tiragem de 2 mil exemplares e tem periodicidade mensal. É vendido em bancas e possui 500 assinantes, não só em Ouro Fino como também em cidades próximas.

Em seu relato, a diretora-executiva contou sobre as dificuldades de manter o jornal circulando:

\begin{abstract}
A Gazeta se tornou muito importante para o município. Afinal, são 126 anos de história. Ela sobrevive com o apoio de alguns anunciantes e assinantes. Recentemente recebeu uma homenagem na Câmara Municipal justamente pelos seus relevantes serviços jornalísticos apresentados nestes últimos anos. Trabalho por amor. A Gazeta mal se sustenta. Sou apenas eu como jornalista responsável por tudo. Há um diagramador e duas representantes comerciais. Tudo que entra da venda dos anúncios e assinaturas mal dá pra cobrir as despesas. Muitas vezes coloco dinheiro do próprio bolso para pagar a gráfica, que é muito cara pelo fato de a Gazeta ser um jornal Standard (FERRAZ, 2018).
\end{abstract}

A Gazeta de Ouro Fino busca se relacionar com seus públicos via e-mail e telefone. E, segundo Ciça Ferraz, pelo fato de a cidade ser pequena, muitos leitores ainda costumam ir a redação, entregar artigos, muitos deles datilografados, relatar histórias para serem publicadas, pagar assinatura.

A diretora-executiva disse que o jornal não tem versão on-line por falta de equipe. Há uma única jornalista responsável, um diagramador e duas representantes comercial.

No Nordeste, o editor-geral do A União, Felipe Gesteira, explicou que o periódico está em processo de evolução para o digital, com modificações no site, mas sem intenção de 
encerrar o impresso. Sobre as estratégias que estão empregando para garantir a sobrevivência do impresso, ele disse que:

\begin{abstract}
A área dos colunistas será ampliada para abrigar todo o corpo de colaboradores de $A$ União, e em breve lançaremos a assinatura digital, para quem mora em cidades onde o impresso não chega, ou, também, para quem prefere o PDF. Além do diário, temos uma edição mensal impressa em Braille, com as notícias mais importantes do mês e alguns artigos selecionados. Este formato atende os deficientes visuais que ainda não usam as novas ferramentas tecnológicas de leitura de texto com auxílio de áudio e se configura como importante arquivo para bibliotecas (GESTEIRA, 2018).
\end{abstract}

A União tem buscado se relacionar com seus públicos por e-mail e por meio das mídias sociais, com perfis no Twitter, Facebook e Instagram. Recebem críticas, sugestões de pautas e artigos para publicação. A tiragem diária do jornal impresso está entre 800 e 900 jornais. Sobre os acessos, em novembro de 2017 foram geradas 887.033 páginas no site (Gesteira, 2018).

Sobre a produção de conteúdo jornalístico, o editor-geral disse que o tratamento é praticamente o mesmo no jornal impresso e no on-line em função de dispor de uma equipe reduzida:

Por termos para o site apenas um profissional e um estagiário, o conteúdo do impresso é publicado no site com poucos ajustes para adequação ao meio, feitos pelo editor. Algumas matérias são exclusivas do site. Publicamos assim quando há necessidade, por exemplo, fatos que acontecem após o fechamento do jornal, ou matérias com forte apelo multimídia, pois o site nos dá a possibilidade de incorporar vídeos (GESTEIRA, 2018).

Sobre a linha editorial, Gesteira afirmou que $A$ União é uma política de comunicação de Estado, "e nunca deve ser usado como jornal do Governo do Estado". Assim, publica as notícias da gestão estadual que são de interesse da população, como obras e serviços, mas, segundo ele, defendem o critério da impessoalidade, por isso, não usam a pessoa do governador como protagonista de qualquer notícia, nem dão destaque a fatos com teor político.

O enfoque da cobertura jornalística é geral, como em um jornal comercial, segundo Gesteira, porém, ele destacou que tem a liberdade de dar destaque a conteúdos que costumam ser suprimidos em outros veículos, como pautas de direitos humanos, ou em defesa de minorias. "Em Diversidade, são explorados temas de posição contra-hegemônica no que diz respeito à grande imprensa, com espaço para pautas que dão visibilidade à população negra, LGBT, quilombolas, ciganos, entre outros" (ibid.). 


\section{Considerações finais}

Neste artigo, buscamos relacionar as principais estratégias de sobrevivência de uma amostra de seis jornais impressos centenários do Brasil, fundados no final do século XIX: $O$ Fluminense (1878); Tribuna do Norte (1882); Gazeta de Minas (1887); O Taquayrense (1887); Gazeta de Ouro Fino (1892); e A União (1893). O objetivo foi observar ações que estão lançando mão no atual contexto de crise do jornalismo e busca por novos modelos de negócio de produção da notícia.

A partir dos depoimentos, verificou-se a questão da importância da marca temporal atingida pelos jornais - ter passado dos 100 anos -, vista como um capital simbólico importante por parte das empresas localizadas em diferentes regiões do Brasil. A tradição é colocada nos discursos como patrimônio e fortalecimento das marcas e como um elemento que contribui, em algum nível, para a manutenção dos periódicos em circulação.

Os jornais têm buscado valorizar a proximidade na abordagem das notícias em busca de atrair os leitores como um valor-notícia fundamental, além do investimento na plataforma da internet e da busca de canais de interação com seus públicos, para receber demandas dos leitores e sugestões de pauta.

Buscam gerar proxemia porque, no interior do quadro geral (informação), disseminado por um suporte técnico (jornal, veículo), abrigam-se os imaginários locais. As pessoas não querem só informação na mídia, mas ver-se, ouvir-se, participar, contar o próprio cotidiano para si mesmas e para aqueles com quem convivem. O público absorve, do conjunto das informações, aquilo que faz vibrar e estabelece comunidade. A comunicação é cada vez mais segmentada, dirigida a um público-alvo (MAFFESOLI, 2004, p.15-16).

Com relação à produção noticiosa, o ponto em comum nas entrevistas foi a questão dos jornais terem equipes reduzidas de jornalistas. Os de maior porte estão atuando com tratamento da notícia de acordo com as características de cada mídia, principalmente impresso e on-line. O Fluminense, por exemplo, tem jornalistas específicos para cada mídia, a fim de garantir o tratamento final à notícia de forma a atender as particularidades de site, da TV e do rádio. Apesar das apurações serem unificadas, querem que os repórteres atuem de forma multimídia, com envio de flashes para o on-line, gravação de vídeos e áudios e entradas ao vivo. 
A Tribuna do Norte conta com uma equipe que produz o conteúdo do impresso que é veiculado da mesma forma no site. A Gazeta de Minas e A União também contam com a mesma equipe para produzir material, mas com veiculação de textos menores na versão online. O Taquaryense e o Gazeta de Ouro Fino não têm versão do jornal na internet.

Os entrevistados dos jornais localizados no interior destacaram que sofrem mais dificuldades em manter os periódicos em circulação em função da concorrência com o jornalismo veiculado na plataforma de internet, que não têm fronteiras físicas; e também em decorrência de manter anunciantes nas áreas em que estão localizados para que a publicidade sustente a viabilidade do jornal impresso junto à venda de assinaturas.

Diante do quadro apresentado, observamos redução de equipes de jornalistas e busca de um modelo de negócio que sustente o jornal. O futuro dos impressos, portanto, segue incerto no contexto de crise do jornalismo.

\section{Referências}

ANDERSON, C.W, BELL, Emily \& SHIRKY, Clay. Jornalismo pós-industrial: adaptação aos novos tempos.

BARBOSA, Marialva. Os donos do Rio - Imprensa, poder e

público. Rio de Janeiro: Vício de Leitura, 2000, 257p. . Jornalistas, "senhores da memória". Trabalho apresentando no Núcleo de Pesquisa de Jornalismo, do IV Encontro dos Núcleos de Pesquisa da Intercom. In: ANAIS do VII Congresso Brasileiro de Ciências da Comunicação Porto Alegre - PUC do Rio Grande do Sul, 30 de agosto a 3 de setembro de 2004.

Como escrever uma história da imprensa? Trabalho apresentado no GT de História do Jornalismo no II Encontro Nacional da Rede Alfredo de Carvalho, realizado em Florianópolis, de 15 a 17 de abril de 2004a.

\section{O que a história pode legar aos estudos de jornalismo. In:}

Contracampo. Revista do Programa de Pós-Graduação em Comunicação - UFF, Niterói1 ${ }^{\circ}$ sem. 2005, n. 12, pp. 51-63. 
Jornalismo e a construção de uma memória para sua história. In:

BRAGANÇA, Aníbal \& MOREIRA, Sônia Virgínia (org.). Comunicação, acontecimento e memória. São Paulo: Intercom, 2005a, p.102-111.

- Mídias e usos do passado: o esquecimento e o futuro. Revista

Galáxia, São Paulo, n. 12, p.13-26, dez. 2006.

. Meios de Comunicação e História: elos visíveis e invisíveis. In:

ANAIS do Congresso Nacional de História da Mídia - São Paulo - 31 maio a 2 de junho de 2007.

Mídias e usos do passado: o esquecimento e o futuro. Galáxia

(PUCSP), vc.12, p.13-26, 2007a.

História Cultural da Imprensa - Brasil - 1900-2000. Rio de

Janeiro: Mauad X, 2007b.

História cultural da imprensa: Brasil, 1800-1900. Rio de Janeiro:

Mauad X, 2010.

O método e a análise história do jornalismo. In: ANAIS do XXXVI

Congresso Brasileiro de Ciências da Comunicação - Manais, AM, 4 a 7/09/2013.

BARBOSA, Marialva \& RIBEIRO, Ana Paula Goulart. "Combates”: por uma história da mídia e do jornalismo no Brasil. In: ANAIS do Intercom 2009 - do XXXII Congresso Brasileiro de Ciências da Comunicação, Curitiba-PR, 4 a 7/09/2009.

. Comunicação e História: um entre-

lugar. In: BARBOSA, Marialva \& RIBEIRO, Ana Paula Goulart (org.). Comunicação e história: partilhas teóricas. Florianópolis: Insular, 2011.

BERGSON, Henri. Matéria e Memória. São Paulo: Editora Martins Fontes, $1^{a}$ edição brasileira, 1990.

GOMES, Nilo Sérgio. Em busca da notícia: memórias do Jornal do Brasil de 1901. In: RIBEIRO, Ana Paula \& FERREIRA, Lucia Maria Alves (orgs.). Mídia e memória: a produção de sentidos nos meios de comunicação. Rio de Janeiro: MauadX, 2007.

GONÇALVES, Janice. Pierre Nora e o tempo presente: entre a memória e o patrimônio cultural. IN: Historiæ, Rio Grande, 3 (3): 27-46, 2012. Disponível em:

https://www.seer.furg.br/hist/article/view/3260/1937. Acesso em 4/08/2017.

HALBWACHS, Maurice. A memória coletiva. São Paulo: Vértice, 1990. 
HOBSBAWM, Eric \& RANGER, Terence (orgs.). A invenção das tradições. Rio de Janeiro: Paz e Terra, 1997, 6 edição, 316p. Coleção Pensamento Crítico - v. 55.

JENKINS, Henry. Cultura da convergência. São Paulo: Aleph, 2ª edição, 2009.

LE GOFF, Jacques. História e Memória. São Paulo: Editora da Unicamp, 1990.

MEYER, Philip. Os jornais podem desaparecer? Como salvar o jornalismo na era da informação. São Paulo: Editora Contexto, 2007.

NORA, Pierre. Entre Memória e História - a problemática dos lugares de memória. In:

Projeto História. São Paulo, n.10, dez. de 1993, p.7-28.

NOVAES, Sonia Barreto de. Lugares de memória e mídias digitais: a narrativa

transversal de Batatuba. Tese de doutorado em Meios e Processos Audivisuais. ECA-USP, 2014.

POLLAK, Michel. Memória, esquecimento, silêncio. In: Estudos Históricos. Rio de Janeiro: vol.2, no 3, 1989, p.3-15.

RANGEL, Sérgio. Jornal do Brasil muda de controlador e volta às bancas no Rio. In:

Folha de S. Paulo em 18/02/2017. Disponível em:

http://www1.folha.uol.com.br/mercado/2017/02/1859877-jornal-do-brasil-muda-de-

controlador-e-volta-as-bancas-do-rio.shtml. Acesso em 10/05/2017.

RÊGO, Ana Regina. A ditadura militar no jornalismo: uma abordagem a partir do

conceito de lugar de memória. In: Revista Brasileira de História da Mídia (RBHM) - v.3, jul.2014- dez.2014.

RIBEIRO, Ana Paula Goulart. Imprensa e história no Rio de Janeiro dos anos 1950. Rio de Janeiro: E-papers, 2007, 362p.

A mídia e o lugar da História. In: HERSCHMANN, Carlos \&

PEREIRA, Carlos Alberto Messeder. Mídia, memória e celebridades - estratégias

narrativas em contextos de altas visibilidades. Rio de Janeiro: E-Papers, 2003, p.87-111.

RIBEIRO, Ana Paula \& FERREIRA, Lucia Maria Alves (orgs.). Mídia e memória: a

produção de sentidos nos meios de comunicação. Rio de Janeiro: MauadX, 2007.

RIBEIRO, Ana Paula Goulart \& HERSCHMANN, Micael (orgs.). Comunicação e história: interfaces e novas abordagens. Rio de Janeiro: editora MauadX, 2008.

RICOEUR, Paul. $O$ Passado tinha um futuro. In: MORIN, Edgar. (Org.). Religação dos saberes: o desafio do século XXI. Rio de Janeiro: Bertrand Brasil, 2001. 
Tempo e Narrativa - Tomo III. Tradução de Roberto Leal Ferreira e revisão técnica de Maria da Penha Villela-Petit. Campinas-SP: Editora Papirus, 1997, 519p. SÁ, Nelson de. “Após 8 anos, 'Jornal do Brasil' reestreia versão impressa”. Folha de S.Paulo, 23/02/2018. Disponível em: https://www1.folha.uol.com.br/mercado/2018/02/apos-

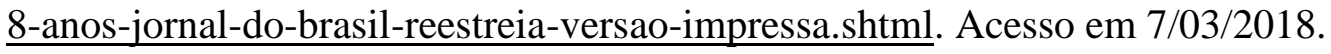

SANTOS, Regma Maria dos. O jornal como lugar de memória: um debate sobre memória coletiva e aceleração do tempo. In: OPSIS - Revista do Niese, V.2, N.2 Jul/ Dez de 2002, p.67-75.

SALAVERRÍA, Ramón; NEGREDO, Samuel (2008) Periodismo integrado: convergencia de medios y reorganización de redacciones. Barcelona: Sol90 Media.

SILVA, Kalina Vanderlei \& SILVA, Maciel Henrique. Dicionário de Conceitos Históricos. São Paulo: Editora Contexto, 2015.

SILVA, Sônia Maria de Menezes da. Os historiadores e os "fazedores de História": lugares e fazeres na produção da memória e do conhecimento histórico contemporâneo a partir da influência midiática. In: Revista OPSIS, Goiânia, v.7, n.09, jul/dez. 2007.

WOLF, Mauro. Teorias da Comunicação. Lisboa, Portugal: Editorial Presença, $5^{\mathrm{a}}$ edição, 1999.

\section{Entrevistas}

BATISTA, Jucélia. Tribuna do Norte. Via e-mail em 6/12/2017.

FERRAZ, Ciça. A Gazeta de Ouro Fino. Via e-mail em 13/03/2018.

FLORES, Pedro Harry Dias. O Taquaryense. Via e-mail em 5/11/2017.

GESTEIRA, Felipe. A União. Via e-mail em 14/01/2018.

RIBEIRO, João Bosco. Gazeta de Minas. Via e-mail em 29/01/2018.

SOUZELLA, Liliane. O Fluminense. Via e-mail em 25/10/2017. 